\title{
How to Attract Students' Visual Attention
}

\author{
Roberto Araya $^{(\bowtie)}$, Danyal Farsani, and Josefina Hernández \\ Centro de Investigación Avanzada en Educación, \\ Universidad de Chile, Santiago, Chile \\ roberto. araya.schulz@gmail.com, \\ danyalfarsani@corpotalk.co.uk, \\ josefina.hernandez@ciae.uchile.cl
}

\begin{abstract}
Attracting students' visual attention is critical in order for teachers to teach classes, communicate core concepts and emotionally connect with their students. In this paper we analyze two months of video recordings taken from a fourth grade class in a vulnerable school, where, every day, a sample of 3 students wore a mini video camera mounted on eyeglasses. We looked for scenes from the recordings where the teacher appears in the students' visual field, and computed the average duration of each event. We found that the student's gaze on the teacher lasted $44.9 \%$ longer when the teacher gestured than when he did not, with an effect size (Cohen's d) of 0.69. The data also reveals different effects for gender, subject matter, and student Grade Point Average (GPA). The effect of teacher gesturing on students with a low GPA is higher than on students' with a high GPA. These findings may have broad significance for improving teaching practices.
\end{abstract}

Keywords: Eye gaze $\cdot$ Hand gestures $\cdot$ Video analysis $\cdot$ Classroom practices

\section{Introduction}

"Culture hides more than it reveals, and strangely enough what it hides, it hides most effectively from its own participants" [20]. This quote fits very well with a Persian proverb and well-known aphorism that has been cited in many ethnographic papers: "a fish is the last creature to discover water". Being immersed in and surrounded by water makes it invisible and almost impossible to notice for the fish. Thus, this paper attempts to scrutinize and reveal the "visibility" and "familiarity" of everyday classroom interactions from the students" perspective, which is often invisible and unfamiliar to us as educators. Our goal is to investigate and reveal some insights into student gazes, trying to achieve an understanding of the situation by closely attending to and documenting the particulars from the students' perspective. Our approach follows Brown's [5] observation that the processes that lead to knowledge construction are habitually and locally situated in nature, as well as Seeley et al.'s [31] observation that "ignoring the situated nature of cognition, education defeats its own goal of providing useable, robust knowledge".

Understanding patterns of classroom interaction between teacher and students, as well as between students themselves, has been an area of interest for teachers. Many ethnographic studies have been conducted to understand the meaning-making practices 
that naturally and normally occur in mainstream schools [10], complementary schools [8] and, in particular, mathematics classrooms [35]. In most studies concerning classroom interaction, an "outsider" enters a classroom, video tapes the lesson, takes field notes and pretends to be a fly on the wall. The outsider's visit to the classroom can last weeks or even months. There is a good chance that the outsider's presence impacts on what is observed. There is therefore a major issue concerning the extent to which an observer affects the situation under observation [9].

Observing involves interpretation by the observer "who has desires and prejudices, sensitivities and propensities" [26]. As observers in the classroom, we observe what we are prepared to observe and we notice what we are sensitized to notice [26]. This fact makes the observer part of the observation. Furthermore, with classroom observation there is no objective place to stand; all observation involves standing somewhere, which subsequently influences what is seen. A classroom observer makes 'choices' and 'decisions' [11] concerning the timing and setting of the observation. For example, during the video recording process we make choices influenced by our "identities and intentions, choices that are also affected by our relationship with the subject" [7]. "The focus of the video camera is selective" [3] and "every camera position excludes other views of what is happening" [17]. Moreover, video recordings produce rich data but only capture a partial view of the social interaction [14]. In practice, recordings that are generated through the lens of a single camera do not capture the whole classroom interaction. The data that is obtained from a single camera has a single focus of attention, whereas students and teachers are capable of focusing on multiple aspects of a complex setting [28]. Therefore, the video recording process can be problematic because there are choices which influence when and whom to record.

Even though there are epistemological issues concerning the validity of data while having a researcher who does not normally belong to the naturally occurring setting, we cannot study the classroom practices outside of its naturally occurring context. "We cannot study the social behavior of a fish by taking him out of water. The child is a child in his world" [4]. Therefore, with the right approach, classrooms can be a natural laboratory for studying situated learning [2]. With this in mind, our approach in this study was to ask students to wear an eyeglass with a mini video camera mounted on it. This way, without having the presence of an "outsider", we would able to observe and document the classroom interaction from the students' own ontological orientations. This approach would enable us to detect who is looking at whom and for how long their visual attention is maintained. Our particular interest for this paper is to identify the students' visual attention on the instruction when the teacher is gesturing, versus when they are not. Furthermore, we want to identify whether the duration of the gaze pattern is different for different subjects. Our study satisfies the fundamental test of research [33], i.e. our results have predictive power. For example, gestures made by the teacher in situated learning are more effective in attracting the students' visual attention. It is particularly important to note that we are able to make predictions, despite the presence of the difficulties suggested by Rudolph, i.e. this is an observation study of classroom practices, which is a very complex environment that depends on several variables, as well as being a "far different phenomena from those studied in controlled laboratory settings" [30]. 


\subsection{The Role of Gestures in Teaching and Learning}

Understanding classroom communication has been a curious and an interesting area of research [32]. However, classroom communication is not only restricted to verbal messages, which has traditionally been the focus of study. An important aspect of communication in teaching and learning is its multimodal nature [13], which is embodied in learning [25]. The term multimodality refers to the complex repertoire of semiotic resources that interlocutors draw on in different social encounters. For example, a multimodal approach involves looking at language and other means of making meaning, such as images, text, graphic symbols, and gestures [22]. In recent years, researchers have looked at how gestures are used in facilitating language production, as well as promoting learner comprehension [1, 24].

Speakers adjust the frequency and size of their gestures in accordance with how likely a gesture is to benefit their listener's understanding [21]. Gestures have been found to complement the verbal message beyond their semantic meaning. Farsani [12] examined a teacher's gestural representation that helped convey both the concept and a new mathematic register to bilingual learners with different levels of English proficiency. In describing the mathematical notion of 'isosceles triangle', the classroom teacher pointed to his eyes as he uttered 'isosceles' in his speech. Phonologically, there is a strong connection between 'isosceles' and how it is pronounced (eye-sosceles). Therefore, the teacher's gesture acted as a mnemonic device to help remember key terminology and a mathematical concept by emphasizing how our eyes are like the two identical sides of an isosceles triangle. Gestures may be more helpful to listeners with weak verbal skills than to listeners with strong verbal skills [21]. However, it is important not to overinflate gestures as interpretive resources. As with any other form of data in qualitative research, gestures are transitory, ephemeral, partial and incomplete, and need to be considered and evaluated in relation to their accompanying verbal message. Particular attention must therefore be paid to 'hearing gestures' [16], in the same way that it is important to 'hear' speech. Speakers often change the size of their gestures, as though they intend for larger gestures to be particularly communicative, while also producing larger gestures when they are describing information that is unknown to their listener or when they are particularly motivated to communicate clearly [21]. Given this, we are therefore interested in discovering to what extent students glean information from their teacher's gestures. What is really happening from the students' perspective when a teacher is gesturing? Where exactly do learners place their visual attention when a teacher is gesturing?

Traditional research into classroom interaction often fails to acknowledge the reciprocal visual attention between students and the classroom teacher. Only recently has technology allowed researchers to look into the 'black box' of classroom practices. For example, a gaze tracker has enabled researchers to document and identify fine-grain information about learners' visual attention in real-time or moment-to-moment activities as they are engaged in their routine classroom practices [15, 29, 34]. As a methodology, gaze tracking seems to be a promising tool for fine-grain analysis of meaning-making practices during classroom communication, as well as student attention. To our knowledge, no previous study has ever analyzed the duration of students' visual attention while the teacher is naturally and spontaneously gesturing 
during his instructional talk. Furthermore, we are interested in examining whether the attention on the teacher is more sustained if the teacher makes gestures, in comparison to instances when no gestures are made.

\section{Process of Data Collection and Analysis}

The data that emerges in this paper is part of a larger dataset which investigated the interactional patterns in a classroom by examining the gaze between students and the classroom teacher [2]. From September 26th, 2012 until November 27th of 2012, a fourth grade classroom teacher and a sample of three students selected each day were asked to wear a mini video camera, which was mounted on eyeglass frames. The original eyeglass lenses were removed so as to minimize the weight and facilitate the original view. Each day, the teacher and students had to wear the eyeglass for approximately six hours. Students took the eyeglasses off during breaks and lunch time, as well as when they went to the bathroom. The class consisted of 36 students ( 21 boys and 15 girls) and the average age of the students was 10.5 years. Both the parents of the students and students themselves gave signed consent to wear these eyeglasses, as well as agreeing to allow any information that was obtained to be disseminated both in professional conferences and in journal articles.

The recordings were manually downloaded at the end of each day. A total of 12,133 min of interactional data was recorded, from which 2,600 min came from the teacher and the rest from the students. In this study, we were primarily interested in looking at instances where the students visually focused on the teacher as he was conveying the instructional information. Considering that the videos had a recording quality of thirty frames per second (30 fps), every second, or every thirty frames, a frame was sampled from the videos. Each frame that was obtained was processed using the OpenCV software in order to detect the presence of faces. A total of 24,148 faces were detected and each face was saved as an image file. Each facial image was then processed semi-automatically using the Google Picasa software in order to identify the subject. Picasa initially identified around $60 \%$ of the faces, and after a few iterations of training, where the software asked us to confirm some of the automatic identifications; it ended up identifying $80 \%$ of the persons. The remaining images, mostly the low-resolution images of faces, were subsequently identified manually.

Of all of the detected and identified faces, there were a total of 857 frames (still images) where students looked at the classroom teacher. In another study [2], we analyzed all the frames, including the gazes among peers. In this particular study we were interested in instances where students kept their focus on the teacher, therefore of the 857 frames where students looked at the classroom teacher, we decided to discard frames where there were other faces (or distractions) present in the same frame. For example, in Fig. 1, we are not sure whether the attention is on the teacher or the other student (given that the OpenCV software identified and saved both faces). We therefore primarily looked at frames where only the teacher's face was present. Furthermore, visibility of the teacher's gestural enactment was essential. Instances where the teacher's hands were blocked due to an obstacle (e.g. a chair, a desk or the student sitting in front) were not considered. Clarity of the frames was also important; therefore if 


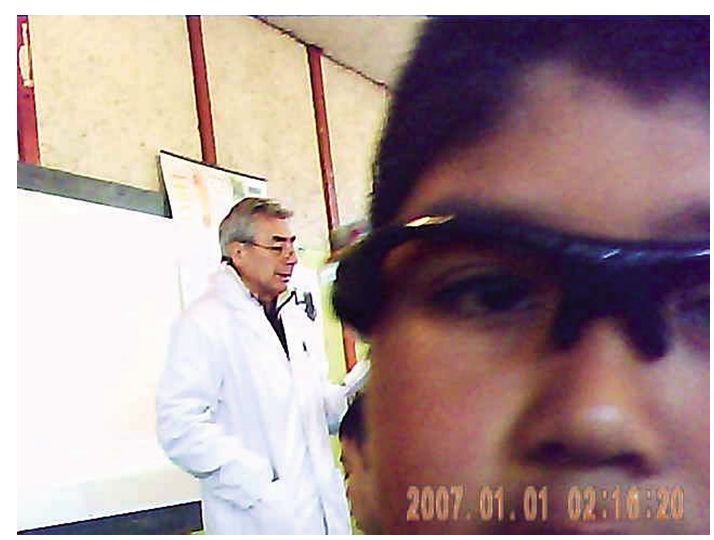

Fig. 1. In this frame, the eye gaze and the attention could be on the teacher, the other boy (who is also wearing the eyeglasses), or on both

a student moved his/her head fast and suddenly, it often generated a blurred frame, which was also discarded. With this restriction, we obtained 264 frames from the total of 857 that were initially generated by the computer.

Furthermore, given the fact that two consecutive frames from the same video camera where the student is looking at the teacher (consecutive meaning that they are only one second apart) do not represent two independent gazes, rather the same gaze that was maintained for more than one second, we define a 'scene' as two or more consecutive frames coming from the same student's camera. Of the 264 frames where the students were looking directly at the teacher, we found 83 scenes, with the shortest containing only two frames, and the longest containing up to ten frames. Of the 83 scenes, 43 scenes correspond to when the teacher made some kind of gesture and 40 scenes correspond to when no gesture was made during his instructional talk.

Using these restrictive categorizations made our interpretation and analysis of the frames more effective. Each of our team members examined every scene in order to look for subtle and silent hand gestures [27]. Reading still images [23] was, indeed, an integral part of the analysis, noting what each student and teacher did, moment by moment. For example, Fig. 2 shows two frames where the classroom teacher is using his gesture space to convey his instructional talk. His gestures can be spontaneous as well as deliberate, synchronous or asynchronous. Gestures could be used to: align with prosodic prominence patterns in his speech (as politicians often do), pantomime to accentuate his verbal message visually, or point to objects or information on the board. The gestures that are employed here could be used for disciplinary remarks and/or pedagogical practices. On the other hand, Fig. 3 illustrates two consecutive frames where the students' gaze is maintained on the teacher, but the teacher is not gesturing. 

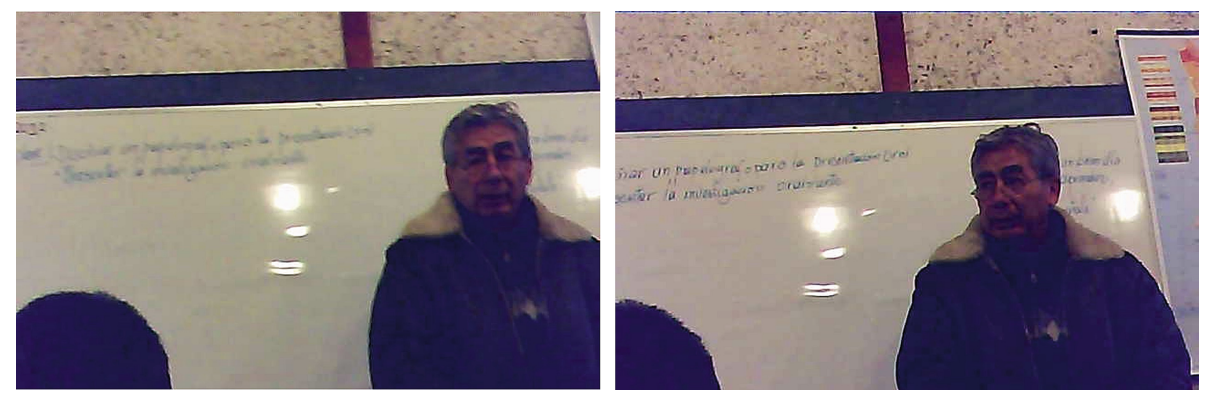

Fig. 2. Two consecutive frames illustrating when the teacher is not gesturing
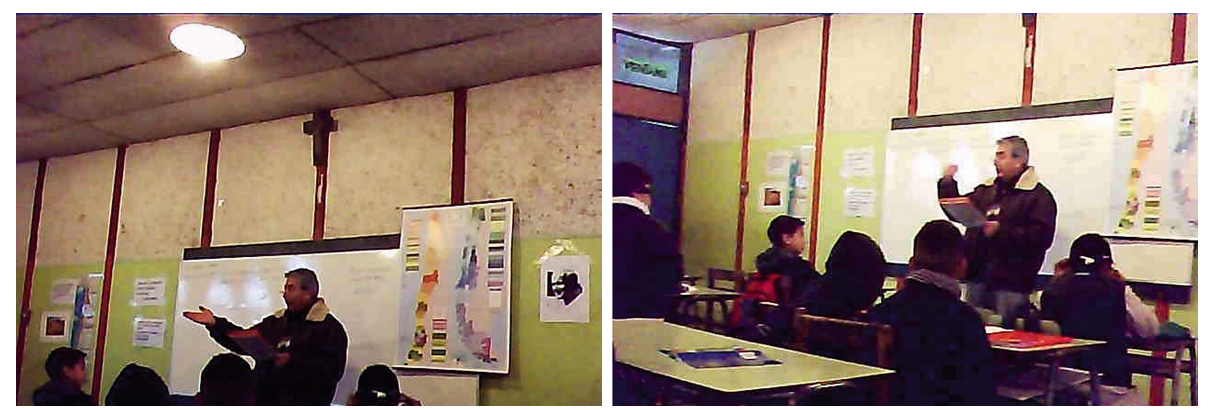

Fig. 3. Two consecutive frames illustrating when the teacher is gesturing

\section{Results and Discussion}

In this paper we consider 'attention' to be the focus of the student's gaze. Of course, this may not always be the case. It is possible for a student to focus on a visual target (teacher) without paying attention to it (i.e. 'looking without observing') and, conversely, paying attention to something without directly focusing on it ('observing without looking') [18]. There is a very crucial and subtle difference between the two. However, in this paper we are assuming that the duration of the students' visual gaze on the teacher is the same as the duration of the students' visual attention on the teacher. With this in mind, we analyzed the moments when a teacher made a gesture as he conveyed his instructional information, in comparison to instances when no gestures were made. What we were particularly interested in identifying was: (1) for each gaze, who is the subject that is looking at the teacher, in terms of their gender and Grade Point Average (averaged annual school grades in the subjects in study, GPA); (2) the duration of the students' visual attention on the instruction while the teacher was gesturing versus when they were not; and (3) whether the duration of a gaze pattern was different for different subjects, specifically in mathematics lessons.

First let us review the mean duration of the students' visual attention on the teacher when no gesture was made. In this sense, there were 40 scenes, each scene containing a minimum of 2 consecutive frames and a maximum of 8 . The analysis revealed a mean 
of $2.58 \mathrm{~s}$, with a standard deviation of 1.24. In contrast, the other group consisted of moments when the teacher gestured during his instructional talk, with a total of 43 scenes comprising 161 frames. In this group, there was a minimum of two consecutive frames and a maximum of 10 consecutive frames, with a mean of $3.74 \mathrm{~s}$ and a standard deviation of 2.04. The difference in the amount of time that students gaze at the teacher when he is gesturing versus when he is not gesturing indicates a $44.9 \%$ increase in the students' visual attention for moments where the teacher gestured, with a p-value of 0.002. We estimated the effect size for different lengths of gaze by calculating Cohen's $\mathrm{d}$, where Cohen's $\mathrm{d}$ is defined as:

$$
\begin{gathered}
d=\frac{\bar{x}_{1}-\bar{x}_{2}}{s}, \\
s=\sqrt{\frac{\left(n_{1}-1\right) s_{1}^{2}+\left(n_{2}-1\right) s_{2}^{2}}{n_{1}+n_{2}-2}} .
\end{gathered}
$$

This gave us a value of 0.69 .

We also analyzed the students according to their GPA, whereby students with an above-average GPA are defined as having a "High GPA" and students with a below-average GPA as having a "Low GPA". We obtained 63 scenes where high GPA students looked at the teacher and only 20 scenes where low GPA students looked at him. Even so, of the 63 scenes when High GPA students look at the teacher, only $46 \%$ correspond to when he is gesturing. In contrast, of the 20 scenes from when the low GPA students look at the teacher, $70 \%$ correspond to when he gestures. The p-value of the difference between these proportions is 0.031 , with a Cohen's $\mathrm{d}$ of 0.48 . This means that low GPA students focus their attention on the teacher more when he gestures than High GPA students, compared with when he does not gesture.

Let us now compare and contrast the students' visual attention in mathematics lessons, compared to all other subjects. For mathematics lessons, we found 29 scenes: 13 from instances where no gestures were made and 16 from moments in which the teacher made gestures. We found a mean of $2.69 \mathrm{~s}$ with a standard deviation of 1.18 for when no gestures were made, versus $3.94 \mathrm{~s}$ for instances when gestures were made, with a standard deviation of 2.41 (p-value 0.1, Cohen's d 0.64). Even though these differences are not statistically significant, there is a $46.8 \%$ increase in the students' visual attention for moments in which the teacher made gestures in the mathematics classrooms. Furthermore, it appears that in mathematics lessons students visually pay more attention to the teacher (regardless of whether he is making a gesture or not) than in any other subject. In addition to this, if the teacher gestures in a mathematics class, $69 \%$ of the students will look at him, whereas when he gestures in other subjects, only $50 \%$ will look at him. The difference in these proportions has a p-value of 0.049 , and Cohen's d of 0.38 (Tables 1 and 2). 
Table 1. Effect of teacher's gestures on the students' visual attention according to GPA, gender and subjects: Effect on the proportion of gazes on the teacher when the teacher gestures

\begin{tabular}{|c|c|c|c|c|c|c|c|}
\hline & $\begin{array}{c}\text { High } \\
\text { GPA } \\
\text { (number } \\
\text { of scenes) }\end{array}$ & $\begin{array}{c}\% \text { of } \\
\text { High } \\
\text { GPA } \\
\text { Students }\end{array}$ & $\begin{array}{l}\text { Low } \\
\text { GPA } \\
\text { (num- } \\
\text { ber of } \\
\text { scenes) }\end{array}$ & $\begin{array}{l}\text { \% of } \\
\text { Low } \\
\text { GPA } \\
\text { Stu- } \\
\text { dents }\end{array}$ & $\begin{array}{l}\text { Compari- } \\
\text { son }\end{array}$ & $\begin{array}{l}\text { P-Value of differ- } \\
\text { ence between the } \\
\text { proportions (one } \\
\text { tail) }\end{array}$ & $\begin{array}{l}\text { Cohen's } \\
\text { D for the } \\
\text { difference } \\
\text { between } \\
\text { the pro- } \\
\text { portion }\end{array}$ \\
\hline $\begin{array}{l}\text { Teacher } \\
\text { gestures }\end{array}$ & 29 & $46 \%$ & 14 & $70 \%$ & $\begin{array}{c}\text { High GPA } \\
\text { vs. Low } \\
\text { GPA: }\end{array}$ & 0.031 & 0.48 \\
\hline $\begin{array}{l}\text { Teacher } \\
\text { does not } \\
\text { gesture }\end{array}$ & 34 & $54 \%$ & 6 & $30 \%$ & & & \\
\hline \multirow[t]{2}{*}{ Total } & 63 & $100 \%$ & 20 & $100 \%$ & & & \\
\hline & $\begin{array}{c}\text { Boys } \\
\text { (number } \\
\text { of scenes) }\end{array}$ & \% of Boys & $\begin{array}{l}\text { Girls } \\
\text { (num- } \\
\text { ber of } \\
\text { scenes) }\end{array}$ & $\begin{array}{l}\% \text { of } \\
\text { Girls }\end{array}$ & & & \\
\hline $\begin{array}{l}\text { Teacher } \\
\text { gestures }\end{array}$ & 35 & $56 \%$ & 8 & $40 \%$ & $\begin{array}{l}\text { Boys vs. } \\
\text { Girls: }\end{array}$ & 0.115 & 0.31 \\
\hline $\begin{array}{l}\text { Teacher } \\
\text { does not } \\
\text { gesture }\end{array}$ & 28 & $44 \%$ & 12 & $60 \%$ & & & \\
\hline \multirow[t]{2}{*}{ Total } & 63 & $100 \%$ & 20 & $100 \%$ & & & \\
\hline & $\begin{array}{c}\text { Math } \\
\text { (number } \\
\text { of scenes) }\end{array}$ & $\begin{array}{l}\% \text { of } \\
\text { Math }\end{array}$ & 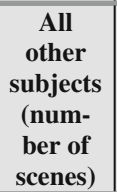 & $\begin{array}{l}\% \text { of all } \\
\text { other } \\
\text { subjects }\end{array}$ & & & \\
\hline $\begin{array}{l}\text { Teacher } \\
\text { gestures }\end{array}$ & 20 & $69 \%$ & 27 & $50 \%$ & $\begin{array}{l}\text { Math vs. } \\
\text { All other } \\
\text { subjects: }\end{array}$ & 0.049 & 0.38 \\
\hline $\begin{array}{l}\text { Teacher } \\
\text { does not } \\
\text { gesture }\end{array}$ & 9 & $31 \%$ & 27 & $50 \%$ & & & \\
\hline Total & 29 & $100 \%$ & 54 & $100 \%$ & & & \\
\hline
\end{tabular}


Table 2. Effect of teacher's gestures on the students' visual attention according to GPA, gender and subjects: Effect on the length of gazes focused on the teacher (measured in seconds) when the teacher gestures

\begin{tabular}{|c|c|c|c|c|c|c|c|c|c|}
\hline & $\begin{array}{l}\text { AVG gaze } \\
\text { when } \\
\text { teacher } \\
\text { does not } \\
\text { gesture (s) }\end{array}$ & SD & $\begin{array}{l}\text { Total } \\
\text { number } \\
\text { of } \\
\text { scenes }\end{array}$ & $\begin{array}{l}\text { AVG gaze } \\
\text { when } \\
\text { teacher } \\
\text { gestures (s) }\end{array}$ & SD & $\begin{array}{l}\text { Total } \\
\text { number } \\
\text { of } \\
\text { scenes }\end{array}$ & Comparison & $\begin{array}{l}\text { P-Value of } \\
\text { diff. } \\
\text { between } \\
\text { length of } \\
\text { gazes (two } \\
\text { tail) }\end{array}$ & $\begin{array}{l}\text { Cohen's } \\
\text { D of diff. } \\
\text { between } \\
\text { the length } \\
\text { of gazes }\end{array}$ \\
\hline $\begin{array}{l}\text { All } \\
\text { students }\end{array}$ & 2.58 & 1.24 & 40 & 3.74 & 2.04 & 43 & $\begin{array}{l}\text { Gesture vs. } \\
\quad \text { No Gesture } \\
\text { for all } \\
\text { students }\end{array}$ & 0.002 & 0.69 \\
\hline High GPA & 2.58 & 1.33 & 34 & 3.69 & 2.05 & 29 & $\begin{array}{l}\text { Gesture vs. } \\
\text { No Gesture } \\
\text { for } \\
\text { High GPA } \\
\text { Students }\end{array}$ & 0.013 & 0.65 \\
\hline Low GPA & 2.50 & 0.55 & 6 & 3.86 & 2.07 & 14 & $\begin{array}{l}\text { Gesture vs. } \\
\quad \text { No Gesture } \\
\text { for } \\
\text { Low GPA } \\
\text { Students }\end{array}$ & 0.136 & 0.76 \\
\hline Boys & 2.43 & 0.74 & 28 & 3.80 & 2.15 & 35 & $\begin{array}{l}\text { Gesture vs. } \\
\text { No Gesture } \\
\text { for Boys }\end{array}$ & 0.002 & 0.82 \\
\hline Girls & 2.92 & 1.98 & 12 & 3.50 & 1.51 & 8 & $\begin{array}{l}\text { Gesture vs. } \\
\text { No Gesture } \\
\text { for Girls }\end{array}$ & 0.489 & 0.32 \\
\hline Math & 2.69 & 1.18 & 13 & 3.94 & 2.41 & 16 & $\begin{array}{l}\text { Gesture vs. } \\
\text { No Gesture } \\
\text { in Math }\end{array}$ & 0.100 & 0.64 \\
\hline $\begin{array}{l}\text { Other } \\
\text { Subjects }\end{array}$ & 2.52 & 1.28 & 27 & 3.63 & 1.82 & 27 & $\begin{array}{l}\text { Gesture vs. } \\
\text { No Gesture } \\
\text { in all other } \\
\text { subjects }\end{array}$ & 0.012 & 0.71 \\
\hline
\end{tabular}

\section{Conclusions and Practical Implications}

Our results not only support previous findings [2], but also reveal more about the nature of students' visual attention with regards to teacher gestures. Although this study only featured one fourth grade classroom, belonging to a district with one of the lowest levels of socioeconomic status in Chile, as well as only one teacher and three students selected every day (with all students wearing the eyeglasses at least twice), the findings have a more general predictive power. As Wieman [33] noted, "a good qualitative study that examines only a few students or teachers in depth will allow one to recognize, and hence more accurately predict, some factors that will be important in educational outcomes and important in the design of larger quantitative experiments in similar populations". Although our study is on a small scale, we can generate precise quantitative predictions with reasonable accuracy regarding what is likely to be observed in student behavior within situated classrooms. 
This paper suggests that students paid more attention to the teacher when the instructional talk was accompanied by gestures. Specifically, if a teacher gestures, this would have a higher effect on students with a Low GPA than students with a higher GPA, as well as on boys. On this matter, a future study would be to analyze if this effect is maintained if the teacher were female instead of male. Given that this study counted only with one male teacher, this may affect the pupil's ability to relate to him, given that students may be sensitive to role models with the same gender. The teacher's gestures in mathematics lessons played an even more crucial role in capturing the students' visual attention. It appears that the students' visual attention on the teacher in mathematics lessons was higher than in other subjects. The teacher's gestures, therefore, appeared to act as nonverbal amplifiers for maintaining the students' visual attention for longer.

The implications of this study raise awareness of how technology can be used to understand fine-grain meaning-making practices during classroom interactions that can be relevant in transforming practice [19]. We would like to conclude this section by reflecting on a recent observation that was made by Castañer and her colleagues [6]. They believe that, regardless of a teacher's experience and qualifications, it is always worth questioning the forms, styles and quality of the messages that are conveyed verbally and nonverbally in their professional teaching practices. We believe that optimization of these very subtle and silent nonverbal messages can have a direct, positive impact on the teaching and learning process. One recommendation and practical application is to incorporate nonverbal training in teacher education courses, both for pre-service and in-service teachers, in order to raise awareness of the communicative function of nonverbal language. In other words, we must not only consider the pedagogical effects of gestures in teaching and learning, but also how these can be used for disciplinary purposes.

The findings of this study open a new window of investigation and give rise to the following future research questions: would we obtain the same results if we had conducted this same experiment in countries where people are known to gesture greatly, or, to the contrary, countries where people are known to be less expressive? And also, what other nonverbal variables affect the flow of interaction between teacher and students, as well as among students themselves?

Acknowledgements. We are thankful to all the Santa Rita School staff; in particular, the enthusiasm and collaboration of the fourth grade teacher Stenio Morales, that was the subject of this paper. We also thank Paulina Sepúlveda and Luis Fredes for the development of the software; to Avelio Sepúlveda, Johan van der Molen, and Amitai Linker for preliminary statistical analysis; to Marylen Araya and Manuela Guerrero for manual classification of faces obtained from the videos; and to Ragnar Behncke for his participation in the design of the measurement strategy and data gathering process. We also thank the Basal Funds for Centers of Excellence Project BF 0003 from CONICYT.

Open Access. This chapter is distributed under the terms of the Creative Commons Attribution 4.0 International License (http://creativecommons.org/licenses/by/4.0/), which permits use, duplication, adaptation, distribution and reproduction in any medium or format, as long as you give appropriate credit to the original author(s) and the source, a link is provided to the Creative Commons license and any changes made are indicated. 
The images or other third party material in this chapter are included in the work's Creative Commons license, unless indicated otherwise in the credit line; if such material is not included in the work's Creative Commons license and the respective action is not permitted by statutory regulation, users will need to obtain permission from the license holder to duplicate, adapt or reproduce the material.

\section{References}

1. Alibali, M.W., Nathan, M.J.: Embodiment in mathematics teaching and learning: Evidence from learners' and teachers' gestures. Journal of the Learning Sciences 21(2), 247-286 (2012)

2. Araya, R., Behncke, R., Linker, A., van der Molen, J.: Mining social behavior in the classroom. In: Núñez, M., Nguyen, N.T., Camacho, D., Trawinski, B. (eds.) ICCCI 2015. LNCS, vol. 9330, pp. 451-460. Springer, Heidelberg (2015). doi:10.1007/978-3-319-24306$1 \_44$

3. Bezemer, J., Mavers, D.: Multimodal transcription as academic practice: a social semiotic perspective. Int. J. Soc. Res. Methodol. 14(3), 191-207 (2011)

4. Birdwhistell, R.: Kinesics and Context: Essays in Body Motion Communication. Penguin, Harmondsworth (1970)

5. Brown, J.S., Collins, A., Duguid, P.: Situated cognition and the culture of learning. Educ. Researcher 18, 32-42 (1989)

6. Castañer, M., Camerino, O., Anguera, M.T., Jonsson, G.K.: Kinesics and proxemics communication of expert and novice PE teachers. Qual. Quant. 47(4), 1813-1829 (2013)

7. Collier, M.: Approaches to analysis in visual anthropology. In: van Leeuwen, T., Jewitt, C. (eds.) Handbook of Visual Analysis, pp. 35-60. Sage publications, Thousands Oaks (2001). London, New Delhi

8. Creese, A., Bhatt, A., Bhojani, N., Martin, P.: Fieldnotes in team ethnography: researching complementary schools. Qual. Res. 8, 223-242 (2008)

9. Emerson, R.M., Fretz, R.I., Shaw, L.L.: Writing Ethnographic Fieldnotes. The University of Chicago Press, Chicago, London (1995)

10. Erickson, F.: What makes a good ethnography "ethnographic"? Coun. Anthropol. Educ. Newslett. 4(2), 10-19 (1973)

11. Erickson, F.: Qualitative methods in research in teaching. In: Linn, R.L., Erickson, F. (eds.) Research in Teaching and Learning, vol. 2, pp. 119-161. Macmillan, New York (1990)

12. Farsani, D.: Deictic gestures as amplifiers in conveying aspects of mathematics register. In: Proceedings of the 9th Conference of European Society for Research in Mathematics Education, Prague, Czech (2015a)

13. Farsani, D.: Making multi-modal mathematical meaning in multilingual classrooms. Unpublished Ph.D. thesis, University of Birmingham (2015b)

14. Flewitt, R.: Using video to investigate preschool classroom interaction: education research assumptions and methodological practices. Vis. Commun. 5(1), 25-51 (2006)

15. Garcia, E., Hannula, H.: Using gaze tracking technology to study student visual attention during teacher's presentation on board. In: Proceedings of the 9th Conference of European Society for Research in Mathematics Education, Prague, Czech (2015)

16. Goldin-Meadow, S.: Hearing Gesture: How Our Hands Help Us Think. Harvard University Press, Cambridge (2003) 
17. Goodwin, C.: Practices of seeing: visual analysis: An ethnomethodological approach. In: van Leeuwen, T., Jewitt, C. (eds.) Handbook of Visual Analysis, pp. 157-182. Sage publications, Thousands Oaks (2001). New Delhi, London

18. Gullberg, M., Kita, S.: Attention to speech-accompanying gestures: eye movements and information uptake. J. Nonverbal Behav. 33, 251-277 (2009)

19. Gutierrez, K., Penuel, R.: Relevance to practice as a criterion for rigor. Educ. Res. 43(1), 19-23 (2014)

20. Hall, E.T.: The Silent Language. Fawcett, Greenwich (1959)

21. Hostetter, A.: When do gestures communicate? A meta-analysis. Psychol. Bull. 137(2), 297-315 (2011)

22. Jewitt, C.: Multimodal discourses across the curriculum. In: Martin-Jones, M., de Mejia, A., Hornberger, N. (eds.) Encyclopedia of Language and Education, Volume 3: Discourse and Education, pp. 357-367. Springer (2008)

23. Kress, G., van Leeuwen, T.: Reading Images: The Grammar of Visual Design. Routledge, London (1996)

24. Lee, O., Fradd, S.H.: Science for all, including students from non-english language backgrounds. Educ. Res. 27, 12-21 (1998)

25. Lindgren, R., Johnson-Glenberg, M.: Emboldened by embodiment: six precepts for research on embodied learning and mixed reality. Educ. Res. 42, 445-452 (2013)

26. Mason, J.: Researching Your Own Practice: The Discipline of Noticing. Routledge, UK (2002)

27. Mehrabian, A.: Silent Messages. Wadsworth, Belmont (1971)

28. Pimm, D.: From Should to Could: reflection on possibilities of mathematics teacher education. Learn. Math. 13(2), 27-32 (1993)

29. Rosengrant, D.: Using eye-trackers to study student attention in physical science classes. Bull. Am. Phys. Soc. 58 (2013). Working paper

30. Rudolph, J.L.: Why understanding science matters the IES research guidelines as a case in point. Educ. Res. 43(1), 15-18 (2014)

31. Seeley, J., Collins, A., Duguid, P.: Situated cognition and the culture of learning. Educ. Res. 18(1), 32-42 (1989)

32. Sinclair, J., Coulthard, M.: Towards an Analysis of Discourse. Oxford University Press, London (1975)

33. Wieman, C.E.: The similarities between research in education and research in the hard sciences. Educ. Res. 43(1), 12-14 (2014)

34. Yang, F.Y., Chang, C.Y., Chien, W.R., Chien, Y.T., Tseng, Y.H.: Tracking learners' visual attention during a multimedia presentation in a real classroom. Comput. Educ. 62, 208-220 (2013)

35. Zevenbergen, R.: Ethnography in the mathematics classroom. In: Malone, J., Atweh, B. (eds.) Aspects of Postgraduate Supervision and Research, pp. 19-38. Lawrence Erbaum \& Association, Mahwah (1998) 